\title{
Targeted RNA Sequencing of VZV-Infected Brain Vascular Adventitial Fibroblasts Indicates That Amyloid May Be Involved in VZV Vasculopathy
}

Andrew N. Bubak, PhD, Christina N. Como, BA, James E. Hassell, Jr., PhD, Teresa Mescher, MPH Seth E. Frietze, PhD, Christy S. Niemeyer, PhD, Randall J. Cohrs, PhD, and Maria A. Nagel, MD

Neurol Neuroimmunol Neuroinflamm 2022;9:e1103. doi:10.1212/NXI.0000000000001103
Correspondence

Dr. Nagel

maria.nagel@ucdenver.edu

\section{Abstract}

\section{Background and Objectives}

Compared with stroke controls, patients with varicella zoster virus (VZV) vasculopathy have increased amyloid in CSF, along with increased amylin (islet amyloid polypeptide [IAPP]) and anti-VZV antibodies. Thus, we examined the gene expression profiles of VZV-infected primary human brain vascular adventitial fibroblasts (HBVAFs), one of the initial arterial cells infected in VZV vasculopathy, to determine whether they are a potential source of amyloid that can disrupt vasculature and potentiate inflammation.

\section{Methods}

Mock- and VZV-infected quiescent HBVAFs were harvested at 3 days postinfection. Targeted RNA sequencing of the whole-human transcriptome (BioSpyder Technologies, TempO-Seq) was conducted followed by gene set enrichment and pathway analysis. Selected pathways unique to VZV-infected cells were confirmed by enzyme-linked immunoassays, migration assays, and immunofluorescence analysis (IFA) that included antibodies against amylin and amyloid-beta, as well as amyloid staining by Thioflavin-T.

\section{Results}

Compared with mock, VZV-infected HBVAFs had significantly enriched gene expression pathways involved in vascular remodeling and vascular diseases; confirmatory studies showed secretion of matrix metalloproteinase- 3 and -10 , as well increased migration of infected cells and uninfected cells when exposed to conditioned media from VZV-infected cells. In addition, significantly enriched pathways involved in amyloid-associated diseases (diabetes mellitus, amyloidosis, and Alzheimer disease), tauopathy, and progressive neurologic disorder were identified; predicted upstream regulators included amyloid precursor protein, apolipoprotein E, microtubule-associated protein tau, presenilin 1, and IAPP. Confirmatory IFA showed that VZV-infected HBVAFs contained amyloidogenic peptides (amyloid-beta and amylin) and intracellular amyloid.

\section{Discussion}

Gene expression profiles and pathway enrichment analysis of VZV-infected HBVAFs, as well as phenotypic studies, reveal features of pathologic vascular remodeling (e.g., increased cell migration and changes in the extracellular matrix) that can contribute to cerebrovascular disease. Furthermore, the discovery of amyloid-associated transcriptional pathways and intracellular amyloid deposition in HBVAFs raise the possibility that VZV vasculopathy is an amyloid disease. Amyloid deposition may contribute to cell death and loss of vascular wall integrity, as

\footnotetext{
From the Department of Neurology (A.N.B., C.N.C., J.E.H., T.M., C.S.N., R.J.C., M.A.N.), University of Colorado; Department of Medical Laboratory Sciences (S.E.F.), University of Vermont, Burlington, VT; Department of Immununology \& Microbiology (R.J.C.), University of Colorado; and Department of Ophthalmology (M.A.N.), University of Colorado, Aurora, co. 


\section{Glossary}

APOE = apolipoprotein E; $\mathbf{A} \boldsymbol{\beta}=$ amyloid-beta; $\mathbf{C A A}=$ cerebral amyloid angiopathy; DEGs = differentially expressed genes; DPI = days postinfection; ECM = extracellular matrix; HBVAF = human brain vascular adventitial fibroblast; IAPP = islet amyloid polypeptide; IFA = immunofluorescence analysis; $\mathbf{M M P}=$ matrix metalloproteinase; $\mathbf{O R F}=$ open reading frame; $\mathbf{P A H}=$ pulmonary arterial hypertension; Thio- $\mathbf{T}=$ Thioflavin $-\mathrm{T} ; \mathbf{V Z V}=$ varicella zoster virus.

well as potentiate chronic inflammation in VZV vasculopathy, with disease severity and recurrence determined by the host's ability to clear virus infection and amyloid deposition and by the coexistence of other amyloid-associated diseases (i.e., Alzheimer disease and diabetes mellitus).

Intracranial varicella zoster virus (VZV) vasculopathy occurs after VZV reactivates from trigeminal or upper cervical ganglia and travels along neurites to nerve termini in the outer adventitia of cerebral arteries. Adventitial fibroblasts are among the first vascular cells to be infected and a robust proinflammatory response follows. Soluble factors secreted by infected cells and inflammatory cells induce vascular damage and pathologic remodeling, characterized by neointima formation, disruption of the internal elastic lamina, and loss of medial smooth muscle cells that leads to ischemic/hemorrhagic stroke, aneurysm, and other cerebrovascular abnormalities. ${ }^{1,2}$ A key feature in VZV vasculopathy pathogenesis is persistent inflammation, disproportionate to the amount of viral antigen present. ${ }^{3}$ Prior studies of VZV-infected primary human brain vascular adventitial fibroblasts (HBVAFs) show that proinflammatory cytokines are secreted, but major histocompatibility complex 1 and programmed death ligand 1 are downregulated, leading to recruitment of inflammatory cells into the vascular wall, but ineffective viral antigen presentation and decreased ability to attenuate inflammation. ${ }^{4,5}$

A novel, yet not mutually exclusive, mechanism for chronic inflammation in VZV vasculopathy emerged from in vitro and in vivo studies showing that VZV induces intracellular amyloid deposition and produces an amyloid-promoting extracellular environment; amyloid is known to be cytotoxic and proinflammatory. ${ }^{6}$ Specifically, VZV-infected astrocytes in vitro contain intracellular amyloid-beta $(\mathrm{A} \beta)$ and islet amyloid polypeptide (IAPP [amylin]) peptides, as well as amyloid, that is not present in uninfected bystander cells. ${ }^{7}$ Furthermore, the conditioned supernatant of infected cultures is amyloid promoting, most likely in part through VZV glycoprotein $B$ peptides that self-aggregate to form amyloid fibrils and the ability of these viral peptides to catalyze aggregation of amyloidogenic cellular peptides. ${ }^{7}$ Compared with control plasma, plasma from patients with acute zoster contains elevated amyloid along with elevated $A \beta 42$ and amylin levels and is also amyloid promoting. ${ }^{8}$ Similarly, compared with stroke controls, CSF from patients with VZV vasculopathy contains elevated amyloid, along with elevated amylin and anti-VZV antibody levels; $A \beta 40$ was reduced and $A \beta 42$ unchanged. ${ }^{9}$ Finally, an observational study of frontal lobes from 2 cases of cerebral amyloid angiopathy (CAA) revealed VZV antigen and DNA colocalizing with $A \beta$ in some of the affected arteries, suggesting that VZV vasculopathy may contribute to CAA pathogenesis through induction of amyloid. ${ }^{10}$ Thus, using targeted RNA sequencing, we investigated whether VZV infection of HBVAFs induced gene expression and pathway signatures consistent with vascular remodeling and amyloid deposition that can contribute to persistent inflammation, as well as disrupt vascular wall integrity.

\section{Methods}

\section{Standard Protocol Approvals, Registrations, and Patient Consents}

HBVAFs used in this study were commercially acquired, and no protocol, approvals, registrations, or patient consents were needed.

\section{Cells and Virus}

Quiescent primary HBVAFs (ScienCell, Carlsbad, CA) were cocultured with either VZV-infected HBVAFs (200 plaqueforming units $/ \mathrm{cm}^{2}$; VZV Gilden strain, GenBank No. MH379685) or uninfected HBVAFs (mock-infected) as described. ${ }^{5}$ Cells and supernatants (spun at $2000 \mathrm{rpm}$ for 5 minutes to eliminate nonadherent $\mathrm{VZV}$-infected cells) ${ }^{11}$ were analyzed at 3 days postinfection (DPI; height of cytopathic effect).

\section{Targeted RNA Sequencing}

The human transcriptome was analyzed using targeted RNA sequencing plates, reagents, protocols, and software according to the manufacturer's instructions (BioSpyder Technologies, Carlsbad, CA). Briefly, 4,000 mock- or VZV-infected HBVAFs were lysed and added to the TempO-Seq 96-well plates containing coded adjacent primer pairs specific for each annotated human transcript. Using a standard thermal cycler, human transcript-specific primers were annealed to the sample RNA; adjacent primer pairs were ligated and then amplified by quantitative PCR. All amplicons were pooled, extracted, concentrated (PCR cleanup kit; Macherey-Nagel, Düren, Germany), and used to construct a single library, which was sequenced on the Illumina NextSeq 500 sequencing platform (Illumina Inc., San Diego, CA). Mapped reads were generated by TempO-SeqR software (BioSpyder 
Technologies) for alignment of demultiplexed FASTQ files from the sequencer to the ligated detector oligomer gene sequences using Bowtie, ${ }^{12}$ allowing for up to 2 mismatches in the 50-nucleotide target sequence. ${ }^{13}$ Differential expression between groups was assessed by TempO-SeqR software, which used the DESeq 2 method for normalization and differential analysis of count data ${ }^{14}$; significantly differentially expressed genes (DEGs) were defined as genes with a padj $<0.05$. The NOISeq $\mathrm{R}$ package was used for quality control and analysis of count data. ${ }^{15}$ Sequencing depth $(\sim 3 \mathrm{M}$ per sample) for both global and protein coding transcripts reached saturation (eFigure 1, A and B, links.lww.com/NXI/ A643). Expression values for RNA biotypes (for genes with $>0$ counts) for treatment groups (eFigure $1, \mathrm{C}$ and $\mathrm{D}$, links. lww.com/NXI/A643) and biodetection plots for individual samples (eFigure 2, links.lww.com/NXI/A643) show comparable sequencing profiles between mock- and VZV-infected HBVAFs.

Pathway enrichment analysis was performed using the hypeR package $^{16}$ and Ingenuity Pathway Analysis software (IPA; Qiagen, Germantown, MD). For hypeR, the upregulated and downregulated DEGs were used for a hypergeometric test (background $=50,000$, FDR $<0.05$ against KEGG gene sets available from Molecular Signatures Database (MSigDB). ${ }^{17,18}$ For IPA, enrichment analysis was performed with the BenjaminiHochberg method to control the false discovery rate (adjusted $p$ value $<0.05$ ). These functional enrichment analyses use computational approaches to identify groups of experimentally observed human genes that are overrepresented or depleted in a curated disease- or biological function-specific gene set. Additional figures were created using Prism 9 (GraphPad Software, San Diego, CA) or the statistical package R. ${ }^{19}$

\section{Multiplex Electrochemiluminescence Immunoassay}

Matrix metalloproteinases (MMPs) in supernatants (MMP$1 / 2 / 3 / 9 / 10$ ) were measured using commercial assays according to the manufacturer's instructions (Mesoscale Discovery, Rockville, MD). MMP concentrations were calculated with reference to a standard curve run on the same plate. All samples were analyzed in duplicate.

\section{Migration Assay}

Migration rates between groups were determined using an 8$\mu \mathrm{m}$ pore transwell migration assay (Sigma-Aldrich, St. Louis, MO); groups included mock-infected HBVAFs, VZVinfected HBVAFs, uninfected HBVAFs exposed to conditioned supernatant from mock-infected cultures, and uninfected HBVAFs exposed to supernatant from VZV-infected cultures. Samples were pipetted into the top chamber; media containing 2\% FBS comprised the lower chamber. After 24 hours, the chamber was removed, and the cells that migrated into the lower chamber were stained with CytoTrack (Life Science, Hercules, CA) according to the manufacturer's instructions and quantified using an Olympus IX73 fluorescence microscope with cellSens imaging software (Olympus Corporation, Center Valley, PA).
Immunofluorescence Antibody Assay and Intracellular Thioflavin-T

\section{Fluorescence Assay}

Quiescent HBVAFs were plated in clear-bottom plates (24-well $\mu$-plate; ibidi, Gräfelfing, Germany) and mock- or VZV-infected. At 3 DPI, cells were analyzed by immunofluorescence analysis (IFA) as described. ${ }^{11}$ In the first set of stainings, cells were incubated with rabbit anti-VZV open reading frame (ORF) 63 antibody $(1: 10,000)^{20}$ and mouse anti-VZV ORF68 antibody (VZV glycoprotein E; 1:500; Santa Cruz Biotechnology, Inc., Dallas, TX) overnight and then probed with secondary antibodies, donkey anti-rabbit Alexa Fluor 488 and donkey anti-mouse Alexa Fluor $594 \mathrm{IgG}$ (both at 1:500, Life Technologies), respectively. Cell nuclei were stained with $2 \mu \mathrm{g} / \mathrm{mL} 4^{\prime}$,6-diamidino-2phenylindole (DAPI, Vector Laboratories, Burlingame, CA). Cells were visualized by confocal microscopy (3I Marianas inverted spinning disk on Zeiss Axio observer Z1; Oberkochen, Germany) and analyzed using 3I Slidebook 6 software.

In the second set of stainings, cells were incubated with mouse anti-VZV glycoprotein B (1:250 dilution; Abcam, Cambridge, $\mathrm{MA})$ and either rabbit anti-A $\beta 42$ (1:100 dilution; Abcam) or rabbit anti-amylin (1:250 dilution; Abcam) antibodies overnight and then probed with secondary antibodies, donkey anti-rabbit Alexa Fluor 647 and donkey anti-mouse Alexa Fluor 594 IgG (both at 1:500, Life Technologies), respectively. Cell nuclei were stained with DAPI (Vector Laboratories). Cells were then stained with Thioflavin-T (Thio$\mathrm{T}$ ) that detects amyloid-like fibrillar structures comprised of amylin, $A \beta$, and/or other amyloidogenic cellular or viral peptides as described ${ }^{7}$; cells were imaged using an Olympus IX73 fluorescence microscope with cellSens imaging software (Olympus Corporation, Central Valley, PA).

\section{Statistical Analysis}

Statistical analyses of MMP secretion and migration assays were performed using GraphPad Prism 9 (GraphPad, San Diego, CA). Statistical differences in MMP secretion between groups was determined by multiple $t$ tests with the 2-stage step-up method of Benjamini, Krieger, and Yekutieli to control for the false discovery rate. Differences in migration rate between treatment groups were determined by independent 2-tailed $t$ tests. Alpha was set at 0.05 .

\section{Data Availability}

The data sets generated and/or analyzed herein are available on the NCBI Gene Expression Omnibus database (GSE175797).

\section{Results}

\section{HBVAFs Are Productively Infected With VZV}

Representative immunofluorescent images of VZV-infected HBVAFs used in this assay are shown in Figure 1. VZVinfected HBVAFs displayed both immediate early (ORF63) and late (ORF68 [VZV glycoprotein E]) viral proteins (Figure 1; white color used in first 2 columns to show 

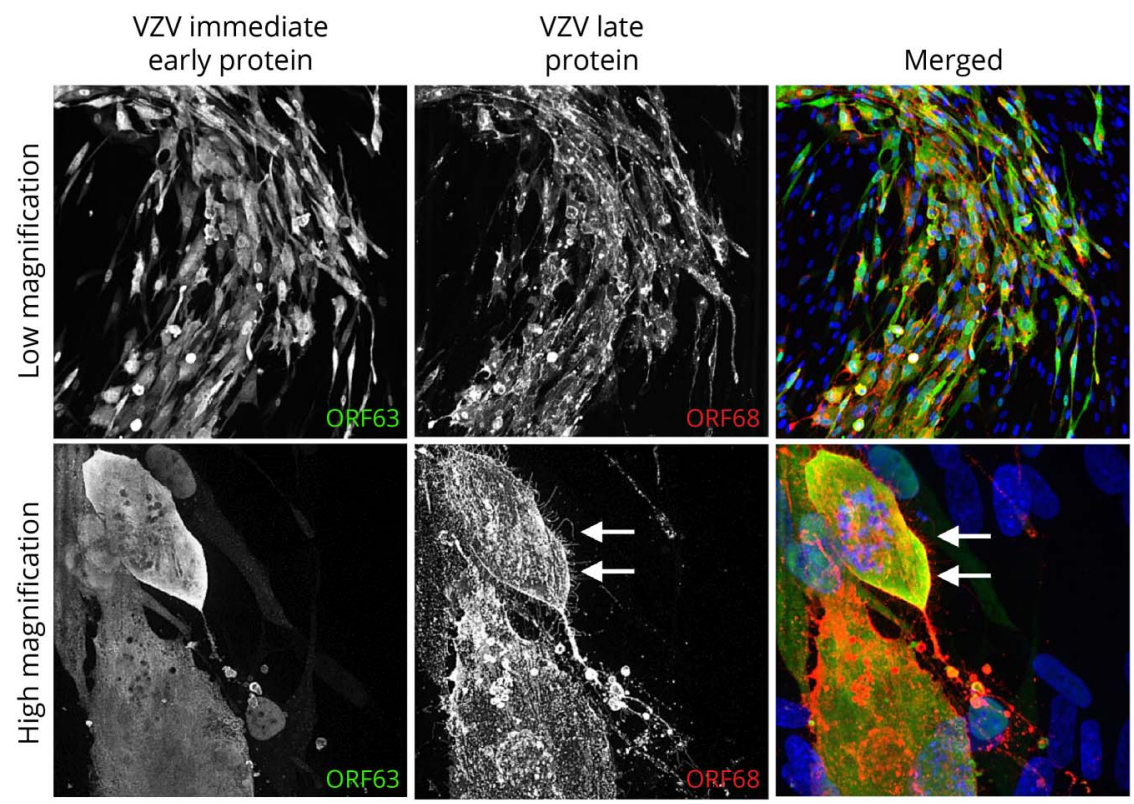

At 3 days postinfection, VZV-infected HBVAFs were fixed and analyzed by IFA using antibodies directed against VZV immediate early and late proteins (VZV ORF63 and VZV ORF68 [VZV glycoprotein E]), respectively. Low- and high-power magnification show ORF63 (green) and ORF68 (red) colocalizing in the same cells (column 3 , merge). Note that cellular projections only contain ORF68 (red arrows, low panels). Magnification $\times 20$, upper panels, and magnification $\times 100$, lower panels. $\mathrm{HBVAF}=$ human brain vascular adventitial fibroblast; ORF = open reading frame; VZV = varicella zoster virus.

morphologic detail) in a cluster of cells, indicating that productive virus infection is occurring. Characteristic VZV glycoprotein E-positive cellular protrusions (arrows, bottom panels; Figure 1) are present that have been previously described. ${ }^{11}$ These cellular protrusions were not positive for the immediate early protein ORF63.

\section{Mock- and VZV-Infected HBVAFs Have Distinct Gene Expression Profiles}

To determine the effect of productive VZV infection on HBVAFs, targeted whole-human transcriptome analysis was performed on mock- and VZV-infected VZV-HBVAFs in triplicate. Principal component analysis demonstrated that replicates from either the mock- or VZV-infected groups cluster together (eFigure 1, E-F, links.lww.com/NXI/A643). Differential gene expression analysis comparing mock- and VZV-infected HBVAFs identified 320 significantly differentially expressed genes (138 upregulated and 182 downregulated) (Figure 2A; eTable 1, links.lww.com/NXI/ A644). Pathway enrichment analysis revealed significantly enriched KEGG gene sets for groups of upregulated and downregulated genes in VZV-infected HBVAFs (Figure 2B; eTable 2, links.lww.com/NXI/A645, sheet "Figure 2B"). The genes downregulated with VZV infection were enriched with focal adhesion and extracellular matrix (ECM) interactions pathways. Several genes previously reported to be downregulated in VZVinfected human epithelial cells ${ }^{21}$ were similarly downregulated in VZV-infected HBVAFs including integrin subunit alpha 1 (ITGA1) and laminin subunit beta 2 (LAMB2) involved in ECM structure (Figure 2C). The pathways upregulated with VZV infection included oxidative phosphorylation, terpenoid biosynthesis, Huntington disease, and Parkinson disease. Examples of genes with increased expression include voltage dependent anion channel 1 (VDAC1) and superoxide dismutase 2 (SOD2) (Figure 2C). Upstream regulator analysis of the VZV DEGs, uncovered candidate transcriptional regulators with roles in cellular proliferation (runt-related transcription factor 3, RUNX3), ${ }^{22}$ innate antiviral immune responses (nuclear factor NF-kappa-B p65 subunit, RELA), ${ }^{23}$ and vascular dementia susceptibility (sterol regulatory element-binding protein 2, SREBF2) ${ }^{24}$ (Figure 2D; eTable 2, links.lww.com/NXI/A645, sheet "Figure 2D"). Of note, we observed a predicted suppression of myocardin related transcription factor $\mathrm{B}, M R T F B$; reduction of this gene leads to vascular defects. ${ }^{25}$ The list of observed DEGs for each upstream regulator is shown in eTable 2, links.lww.com/NXI/A645. Overall, these data show that VZV infection elicits distinctive gene expression changes in HBVAFs.

\section{VZV-Infected HBVAFs Are Enriched for Gene Sets Consistent With Vascular Diseases and Remodeling}

To further investigate the physiologic pathways associated with vascular disease, we performed enrichment analysis using the disease and functions data set in IPA. Specifically, compared with mock, VZV-infected HBVAFs were enriched for disorder of blood vessel, infarction, vaso-occlusion, familial vascular disease, cerebral disorder, progressive neurologic disorder, aneurysm, vascular lesion, chronic inflammatory disorder, and cerebrovascular dysfunction (Figure 3A; list of observed DEGs in each pathway shown in eTable 3, links.lww. com/NXI/A646). Furthermore, gene sets associated with disrupted vessel morphology were also noted, including vasculogenesis, migration of cells, morphology of vasculature, organization of ECM, abnormal morphology of vasculature, 
A

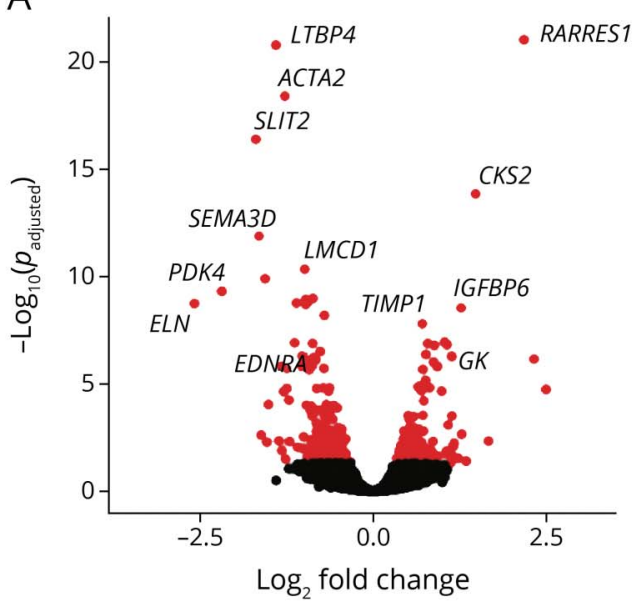

B

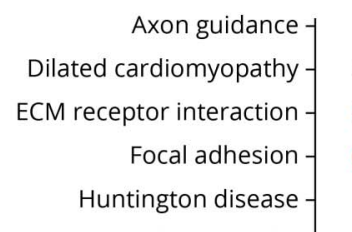

Hypertrophic cardiomyopathy -

MAPK signaling pathway -

Oxidative phosphorylation

Parkinson disease

Pathogenic E.coli infection

Pathways in cancer

Pyruvate metabolism

Regulation of actin cytoskeleton

Small cell lung cancer

Terpenoid backbone biosynthesis

TGF- $\beta$ signaling pathway

Vascular smooth muscle contraction -

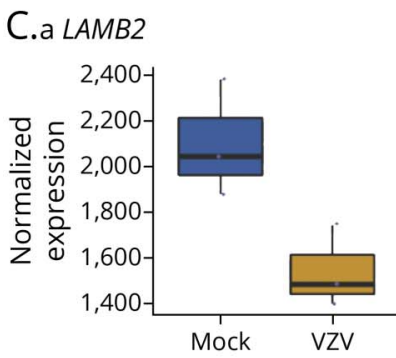

C.b ITGA1

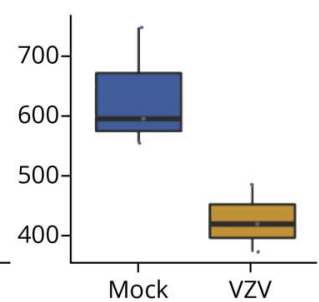

C.c VDAC1

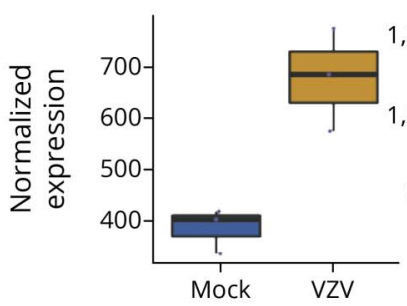

C.d SOD2

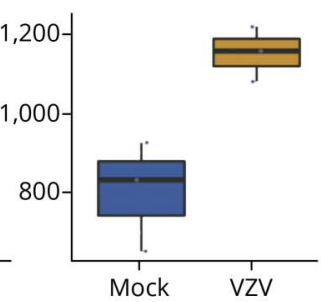

D

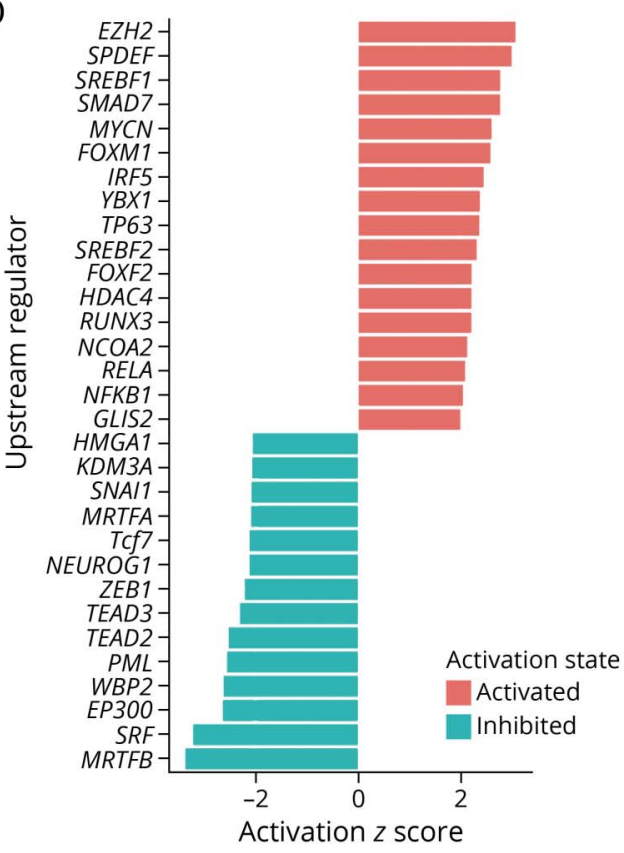

(A) Volcano plot depicting the differential gene expression between mock- and VZV-infected HBVAFs ( $\mathrm{n}=3$ ); red circles are genes that are significantly differentially expressed (padj <0.05) in VZV-infected cells compared with mock; the most statistically significant genes are labeled. (B) KEGG pathway enrichment analysis of downregulated and upregulated genes (x-axis); each dot corresponds to a KEGG gene set, the color represents the significance, and the size signifies the gene set size. (C) Examples of genes downregulated and upregulated in VZV-infected HBVAFs. Shown in the boxplot are the DESeq2 normalized counts for each gene. (D) Predicted upstream transcriptional regulators that may account for the altered gene expression profiles observed during VZV infection. The barplot represents the IPA activation Z-score for all significant upstream transcriptional regulators ( $p$ adj $<0.05$ ), blue is inhibited $(<-1.8 \mathrm{Z}$-score), and red is activated (>1.8 Z-score). HBVAF = human brain vascular adventitial fibroblast; VZV = varicella zoster virus.

migration of vascular cells, proliferation of vascular cells, cellular infiltration, and cell movement of fibroblasts (Figure 3B; list of observed DEGs in each pathway shown in eTable 3, links.lww.com/NXI/A646). To confirm select transcriptional findings (i.e., organization of cellular matrix and migration of cells/migration of vascular cells/cellular infiltration/cell movement of fibroblasts), MMPs secreted into conditioned supernatants from mock and VZV-infected HBVAFs were analyzed, and a functional cellular migration assay was performed. Compared with mock, VZV-infected conditioned supernatant contained significantly higher MMP-3 and MMP10 , supporting an alteration in the extracellular matrix; no changes were observed in MMP-1,-2, or -9 (Figure 3C). VZVinfected HBVAFs migrated at a significantly higher rate than mock-infected cells supporting the cell migration pathways identified (Figure 3D). This result was also seen, albeit to a lower degree, when conditioned supernatant from VZVinfected HBVAFs was placed on naive HBVAFs, suggesting 
Figure 3 VZV Infection of HBVAFs Is Associated With Vascular Disease and Altered Vessel Morphology Transcriptional Pathways

A. Vascular diseases

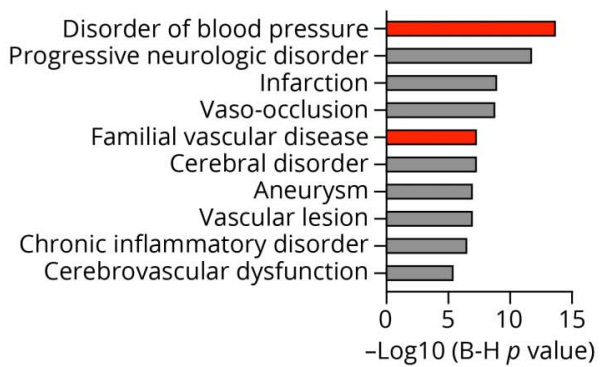

C

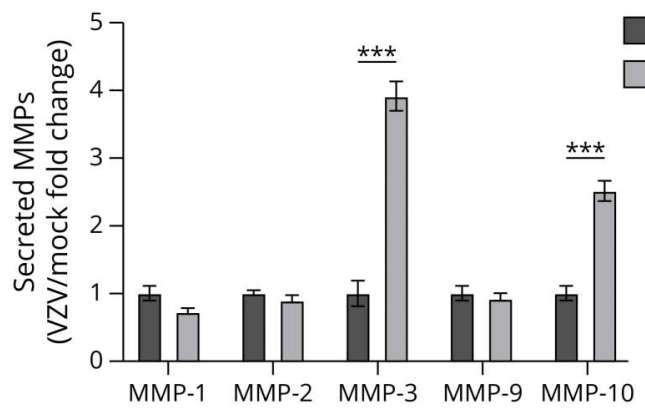

B. Vessel morphology
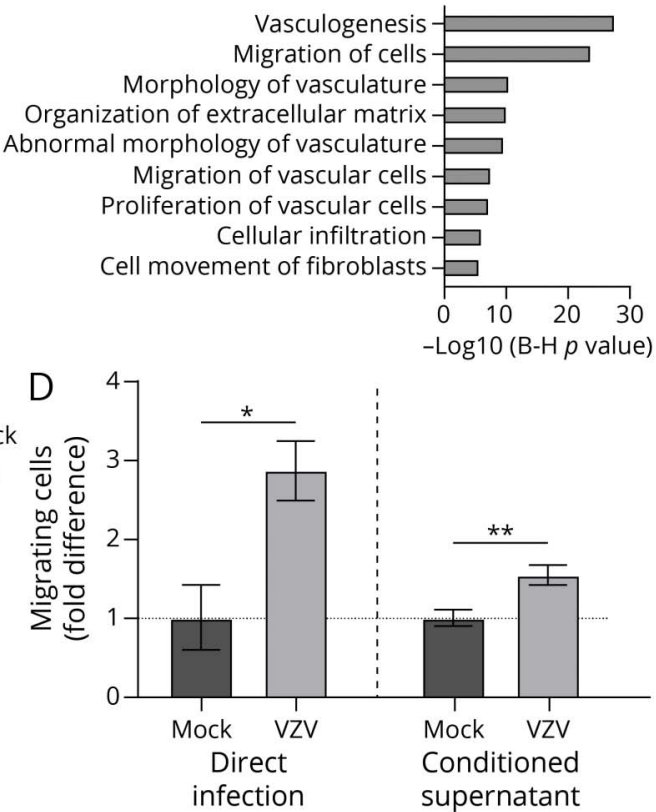

Gene expression and pathway analysis identified in VZV-infected HBVAFs were compared with mock-infected HBVAFs. (A) Significantly altered pathways involved in vessel morphology were seen (red denotes activated, and gray denotes significantly altered but unknown direction). (B) Significantly altered pathways involved in vascular diseases were present. (C) To support gene expression pathways leading to organization of extracellular matrix and cellular infiltration, MMPs in conditioned supernatant from VZV-infected HBVAFs compared with mock supernatant were measured by multiplex ELISAs. VZV-infected HBVAFs secreted significantly more MMP-3 and MMP-10 compared with mock at 3 days postinfection (DPI); (D) Cell migration assays were used to support gene expression pathways associated with migration of cells and vascular cells and cell movement of fibroblasts. VZV-infected HBVAFs had a significantly increased number of migratory cells in the assay compared with mock-infected cells. Uninfected HBVAFs exposed to conditioned supernatant from VZV-infected cells had increased migration compared with cells exposed to supernatant from mock-infected cells, indicating that infected cells secrete soluble factors that increase migration of bystander cells. HBVAF = human brain vascular adventitial fibroblast; MMP = matrix metalloproteinase; VZV = varicella zoster virus. ${ }^{\star} p<0.05,{ }^{\star *} p<0.01,{ }^{\star * \star} p<0.001$.

that a soluble factor contributed, in part, to enhanced cell migration (Figure 3D).

\section{VZV-Infected HBVAFs Show Both Transcriptional and Protein Signatures Consistent With Amyloid Deposition}

To extend the in vitro and in vivo studies that suggest a causal role for VZV in amyloid production and accumulation, ${ }^{7-9}$ the VZV-infected HBVAFs transcriptional profiles were interrogated and revealed signatures relevant to amyloidassociated diseases. Significant enrichment in pathways, such as diabetes mellitus, amyloidosis, dementia, tauopathy, and Alzheimer disease, was observed (Figure 4A; list of observed DEGs in each pathway shown in eTable 3, links.lww.com/NXI/ A646). Furthermore, multiple upstream regulators involved in these diseases were also significantly enriched, including amyloid precursor protein $(A P P)$, apolipoprotein $\mathrm{E}(A P O E)$, microtubule-associated protein tau $(M A P T)$, presenilin 1 (PSEN1), and IAPP (amylin), (Figure 4B; list of observed DEGs for each upstream regulator is shown in eTable 3, links.lww.com/NXI/ A646). Confirmatory IFA revealed colocalization of VZV gB (red), A $\beta 42$ (yellow), and Thio-T (green) in VZV-infected HBVAFs, but not in bystander cells or mock-infected cells (Figure 4C). Similarly, VZV-infected HBVAFs showed colocalization of VZV gB (red), amylin (yellow), and Thio-T (green) that was absent in bystander cells and mock-infected cells (Figure 4D). Overall, these findings suggest that direct VZV infection of HBVAFs can lead to amyloid production.

\section{Discussion}

Intracranial VZV vasculopathy, due to productive VZV infection of cerebral arteries, is characterized by persistent inflammation that damages the vascular wall, leading to stroke, aneurysm, and other cerebrovascular abnormalities. Mechanisms of persistent inflammation are not fully characterized, but recent studies show that VZV infection in vitro and in vivo can increase intracellular and extracellular amyloid ${ }^{7-9}$; if amyloid is not cleared efficiently, because of host or environmental factors (i.e., age-related decreases in glymphatic clearance or MMPs that catabolize amyloid) or ongoing virus replication, amyloid deposits can persist in tissue and serve as a nidus for ongoing inflammation and cytotoxicity. Herein, we examined VZV-infected HBVAFs, which are among the first cerebrovascular cells infected following VZV reactivation and spread to cerebral arteries. Targeted RNA sequencing revealed that VZV-infected HBVAFs had significantly enriched gene expression pathways for vascular remodeling, vascular diseases, amyloidosis, and Alzheimer disease 
A. Amyloid-associated diseases

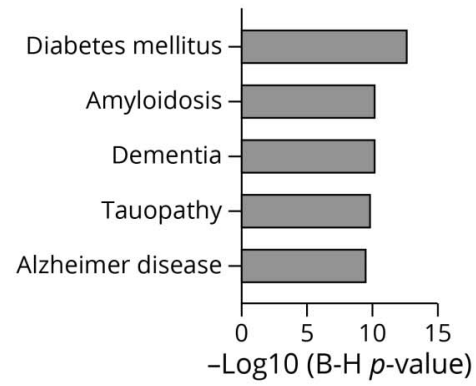

B. Predicted upsteam regulators

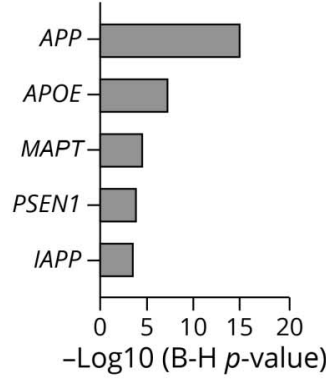

A 342

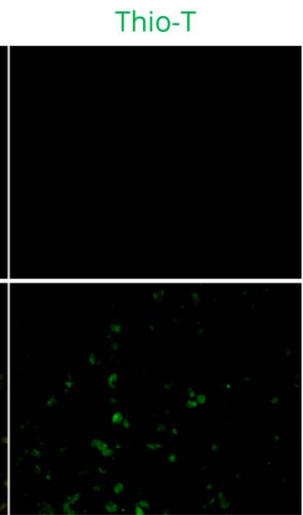

Thio-T

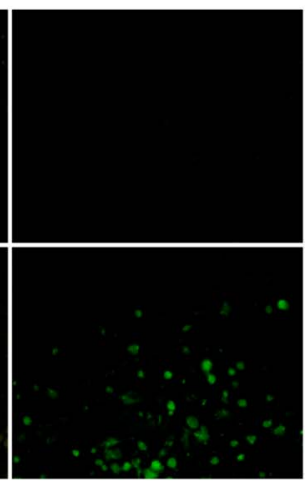

Gene expression and pathway analysis identified in VZV-infected HBVAFs were compared with mock-infected HBVAFs. (A) Significantly enriched pathways involved in amyloid-associated diseases were found. (B) Predicted, significantly enriched upstream regulators relevant to amyloid-associated diseases were identified. To support gene expression pathways of amyloidosis, mock- and VZV-infected HBVAFs were analyzed by an immunofluorescence assay using antibodies against VZV glycoprotein B (VZV gB, red) and either A 342 or amylin (yellow); slides were subsequently stained with Thioflavin-T (Thio-T, green) that detects amyloid-like fibrillar structures. (C) Mock-infected cells did not contain VZV gB, Aß42, or Thio-T (upper panels). VZV-infected cells contained VZV gB, Aß42, and Thio-T (lower panels). (D) Mock-infected cells did not contain VZV gB, amylin, or Thio-T (upper panels). VZV-infected cells contained VZV $\mathrm{gB}$, amylin, and Thio-T (lower panels). Cell nuclei (blue). Magnification $\times 20$. $\mathrm{HBVAF}=$ human brain vascular adventitial fibroblast; VZV = varicella zoster virus. compared with mock-infected cells. Additional studies confirmed select RNA sequencing results. Specifically: (1) VZVinfected HBVAF supernatant had significantly increased MMP3 and MMP-10 compared with mock-infected supernatant; (2) VZV-infected HBVAFs had an increased migratory phenotype compared with mock-infected cells; (3) uninfected HBVAFs exposed to supernatant from VZV-infected cells had increased migration compared with supernatant from mock-infected cells; and (4) VZV-infected HBVAFs contained intracellular $\mathrm{A} \beta 42$, amylin, and amyloid. Several findings are noteworthy that address the vascular remodeling seen in VZV vasculopathy and the potential role of amyloid.

Pathway analysis revealing enhanced cell migration and ECM changes during VZV infection is consistent with other vasculitides. We confirmed these results and found that phenotypically,
VZV-infected HBVAFs were hypermigratory compared with mock-infected HBVAFs and secreted increased MMP-3 and MMP-10 that would degrade the extracellular matrix and facilitate pathologic vascular remodeling if activated. Elevated MMP-3 in the supernatant of VZV-infected HBVAFs has been previously reported, along with elevated MMP-1 and MMP-9, which we did not observe; MMP-10 was not measured in that previous report. ${ }^{26}$ This discrepancy may be due to the later time of analysis in the earlier report (6 DPI compared with our 3 DPI analysis), as well as differences in VZV strains; the earlier report used the VZV Ellen strain, whereas we used a low-passage clinical isolate strain (VZV Gilden strain). Importantly, we found that conditioned supernatant from VZV-infected HBVAFs contains soluble factors that can affect uninfected cells and confer a hypermigratory phenotype. This observation is consistent with a pulmonary arterial hypertension $(\mathrm{PAH})$ study showing that conditioned 
supernatant from adventitial fibroblasts derived from calves with PAH conferred a hypermigratory phenotype to THP-1 monocytes. $^{27}$ Furthermore, Eleftheriou et al. ${ }^{28}$ also showed that VZVinfected HBVAFs are hypermigratory and release microparticles containing virions. Whether circulating microparticles containing viral proteins or host factors (i.e., interleukin-6, etc.) induces this functional response is currently unknown. Nonetheless, the ability of infected cells to confer a hypermigratory phenotype to surrounding uninfected cells may explain, in part, the extensive accumulation of myofibroblasts in the neointima of VZV vasculopathy arteries despite viral antigen being present in only a small number of vascular cells. ${ }^{1}$

A striking result was the absence of human gene sets demonstrating robust virus infection, innate antiviral responses, interferon signaling, or immune cell activation, although chronic inflammatory disease was enriched. This result is discordant with the observed inflammation in VZV-infected arteries acquired postmortem from patients with VZV vasculopathy, ${ }^{1}$ but may perhaps be explained by the early times that VZV-infected HBVAFs were analyzed (3 DPI compared with weeks-months after infection in patient arteries) and the absence of other adventitial cells in our cultures that may trigger the inflammatory cascade (e.g., dendritic cells). Our results are most consistent with previous studies of these VZV-infected HBVAFs showing an early suppression of antiviral responses. At 3 DPI, compared with IFN- $\alpha$-treated controls, phosphorylated STAT1 did not translocate to the nucleus in VZVinfected HBVAFs, resulting in impaired downstream expression of interferon-inducible antiviral $\mathrm{Mx} 1 .{ }^{29}$ In addition, it has also been reported that VZV infection of primary human astrocytes does not result in a robust inflammatory response at 3 DPI, whereas VZV infection of human perineurial cells did, suggesting cell-specific responses to VZV infection. ${ }^{30}$ Thus, during early VZV infection of adventitial fibroblasts in the artery, there is likely suppression of antiviral responses. As infection progresses, this suppression may be overcome through yet uncharacterized mechanisms, and inflammation ensues.

Our findings that VZV infection of HBVAFs produce gene expression pathways for amyloid disease and that the infected cells contain intracellular amyloid raise the tantalizing notion that VZV vasculopathy is an amyloid-associated disease. Previous studies strongly support this hypothesis. ${ }^{7-10}$ The first link between VZV infection and amyloid was seen in mock- and VZV-infected primary human spinal astrocytes, among the first CNS cells to be infected after VZV reactivation from peripheral ganglia and spread to the spinal cord. ${ }^{7}$ In the infected astrocyte, VZV induced intracellular expression of host cellular peptides that had the capacity to misfold and form amyloid (A $\beta 42$ and amylin); these same cells also contained amyloid that was not present in uninfected bystander cells. The conditioned supernatant from VZV-infected cells induced spiked A $\beta 42$ and amylin to form amyloid fibrils by electron microscopy, more so than mock supernatant. Finally, this report demonstrated that VZV gB peptides could self-aggregate and form amyloid fibrils, as well as catalyze the aggregation of $A \beta 42$ and amylin, suggesting that as infected cells are lysed, intracellular amyloid and amyloidogenic cellular and viral peptides are released into an extracellular environment that promotes further aggregation. This in vitro study was corroborated by 2 in vivo studies. The first study found that compared with 10 control plasma, 14 acute zoster plasma had significantly elevated amyloid along with elevated A $\beta 42$ and amylin levels; zoster plasma increased amyloid aggregation with addition of exogenous $A \beta 42$ or amylin. ${ }^{8}$ The second study of 16 patients with VZV vasculopathy and 36 stroke controls found that VZV vasculopathy CSF had significantly increased amyloid along with increased amylin and anti-VZV antibody levels; $A \beta 40$ was reduced and $A \beta 42$ unchanged. ${ }^{9}$ In the same report, primary human perineurial cells that surround nerve fibers innervating adventitia were also mock and VZV infected and found to have intracellular amylin, $\mathrm{A} \beta 42$, and amyloid, similar to our VZV-infected HBVAFs. Of note, amylin knockdown decreased VZV cDNA, indicating that it had a proviral function during VZV infection. Because VZV vasculopathy and CAA have similar clinical presentations (both affect cerebrovasculature in the elderly, produce hemorrhage, and can have a protracted course of cognitive decline and other neurologic deficits), frontal lobes from 2 CAA cases were examined for the presence of $\mathrm{VZV} .{ }^{10} \mathrm{VZV}$ antigen colocalized with $\mathrm{A} \beta$ in some affected arteries from 2 CAA cases, suggesting a possible association between VZV infection and CAA. ${ }^{10} \mathrm{Fi}$ nally, because the e4 allele of APOE (APOE-e4) is associated with severe $\mathrm{CAA}^{31}$ and homozygosity of APOE-e4 has also been linked to zoster susceptibility in females, ${ }^{32}$ determining the frequency of APOE-e4 and VZV vasculopathy susceptibility would be informative and further strengthen the link between VZV and amyloid-associated diseases.

Although VZV infection of cerebral arteries may lead to amyloid deposition, host responses may dictate the efficiency of amyloid clearance and resolution of the vasculitis. For instance, VZV vasculopathy in children tends to be monophasic, whereas in older adults, it can recur. Differences in amyloid accumulation, clearance, and immune responses between young and aged brains are well known ${ }^{33}$ and may be an important factor mediating the recurrence and severity differences in VZV vasculopathies between adults and children. For example, not only are amyloid efflux mechanisms reduced with normal aging, ${ }^{34}$ it has also been shown that fibrillar A $\beta 42$ injections into the brain of aged, but not young rhesus macaques, resulted in substantial neurodegenerative pathology, 35 suggesting a vulnerability of an aged brain to amyloid toxicity. Furthermore, microglia from aged brains have markedly reduced phagocytic activity against amyloid ${ }^{36}$; amyloid phagocytosis by aged microglia results in a redistribution of amyloid rather than protein breakdown ${ }^{37}$ (reviewed in Spittau ${ }^{38}$ ).

Given the evidence that VZV vasculopathy may be an amyloid-associated disease, by extension, VZV vasculopathy may also increase the amyloid burden of other amyloidassociated diseases, such as Alzheimer disease, and accelerate clinical decline. This is further supported by epidemiologic studies showing that VZV reactivation (herpes zoster) 
increases the risk of dementia, and antiviral therapy reduces the risk, ${ }^{39-41}$ and increased the risk of neovascular macular degeneration, ${ }^{42}$ both characterized by $A \beta 42 /$ amylin and $A \beta 42$ aggregates, respectively. In addition, zoster is associated with a deterioration in glycemic control in diabetes mellitus ${ }^{43}$ that is characterized by amylin aggregates in the pancreas that contribute to death of insulin-producing beta cells. ${ }^{44-46}$

Overall, there is mounting evidence that VZV vasculopathy is an amyloid-associated disease and virus-induced deposition of amyloid may serve as a nidus for persistent inflammation and cytotoxicity, depending on host and environmental factors that contribute to efficient or deficient amyloid clearance. Examination of VZV antigen and amyloid in postmortem virus-infected arteries from patients with VZV vasculopathy is warranted in future studies. Finally, our results suggest that in individuals with amyloid-associated diseases, VZV reactivation that can occur with or without rash should be considered a potential accelerator of disease progression, and these individuals may benefit from rapid antiviral therapy during reactivation or zoster vaccination to prevent reactivation.

\section{Acknowledgment}

The authors thank Cathy Allen for manuscript preparation and the BioFrontiers Institute Next-Gen Sequencing Core Facility, which performed the Illumina sequencing. Randall J. Cohrs, $\mathrm{PhD}$, is deceased.

\section{Study Funding}

This work was supported by grant AG032958 from the NIH to M.A. Nagel and R.J. Cohrs.

\section{Disclosure}

The authors report no disclosures. Go to Neurology.org/NN for full disclosures.

\section{Publication History}

Received by Neurology: Neuroimmunology \& Neuroinflammation July 7, 2021. Accepted in final form September 9, 2021.

\section{Appendix Authors}

\begin{tabular}{|c|c|c|}
\hline Name & Location & Contribution \\
\hline $\begin{array}{l}\text { Andrew N. } \\
\text { Bubak, } \\
\text { PhD }\end{array}$ & $\begin{array}{l}\text { Department of Neurology, } \\
\text { University of Colorado, } \\
\text { Aurora, CO }\end{array}$ & $\begin{array}{l}\text { Drafting/revision of the } \\
\text { manuscript for content, } \\
\text { including medical writing for } \\
\text { content; major role in the } \\
\text { acquisition of data; study } \\
\text { concept or design; analysis or } \\
\text { interpretation of data; and } \\
\text { additional contributions: } \\
\text { statistical analysis }\end{array}$ \\
\hline $\begin{array}{l}\text { Christina } \\
\text { N. Como, } \\
\text { BA }\end{array}$ & $\begin{array}{l}\text { Department of Neurology, } \\
\text { University of Colorado, } \\
\text { Aurora, CO }\end{array}$ & $\begin{array}{l}\text { Drafting/revision of the } \\
\text { manuscript for content, } \\
\text { including medical writing for } \\
\text { content; additional } \\
\text { contributions: acquisition of } \\
\text { data }\end{array}$ \\
\hline
\end{tabular}

Appendix (continued)

\begin{tabular}{|c|c|c|}
\hline Name & Location & Contribution \\
\hline $\begin{array}{l}\text { James E } \\
\text { Hassell, Jr., } \\
\text { PhD }\end{array}$ & $\begin{array}{l}\text { Department of Neurology, } \\
\text { University of Colorado, } \\
\text { Aurora, CO }\end{array}$ & $\begin{array}{l}\text { Drafting/revision of the } \\
\text { manuscript for content, } \\
\text { including medical writing for } \\
\text { content, and analysis or } \\
\text { interpretation of data }\end{array}$ \\
\hline $\begin{array}{l}\text { Teresa } \\
\text { Mescher, } \\
\text { MPH }\end{array}$ & $\begin{array}{l}\text { Department of Neurology, } \\
\text { University of Colorado, } \\
\text { Aurora, CO }\end{array}$ & $\begin{array}{l}\text { Drafting/revision of the } \\
\text { manuscript for content, } \\
\text { including medical writing for } \\
\text { content, and additional } \\
\text { contributions: acquisition of } \\
\text { data }\end{array}$ \\
\hline $\begin{array}{l}\text { Seth E. } \\
\text { Frietze, } \\
\text { PhD }\end{array}$ & $\begin{array}{l}\text { Department of Medical } \\
\text { Laboratory Sciences, } \\
\text { University of Vermont, } \\
\text { Burlington, VT }\end{array}$ & $\begin{array}{l}\text { Drafting/revision of the } \\
\text { manuscript for content, } \\
\text { including medical writing for } \\
\text { content; analysis or } \\
\text { interpretation of data; and } \\
\text { additional contributions: } \\
\text { statistical analysis }\end{array}$ \\
\hline $\begin{array}{l}\text { Christy S. } \\
\text { Niemeyer, } \\
\text { PhD }\end{array}$ & $\begin{array}{l}\text { Department of Neurology, } \\
\text { University of Colorado, } \\
\text { Aurora, CO }\end{array}$ & $\begin{array}{l}\text { Drafting/revision of the } \\
\text { manuscript for content, } \\
\text { including medical writing for } \\
\text { content, and analysis or } \\
\text { interpretation of data }\end{array}$ \\
\hline $\begin{array}{l}\text { Randall J. } \\
\text { Cohrs, PhD }\end{array}$ & $\begin{array}{l}\text { Department of Neurology, } \\
\text { University of Colorado, } \\
\text { Aurora, CO; Department of } \\
\text { Immununology \& } \\
\text { Microbiology, University of } \\
\text { Colorado, Aurora, CO }\end{array}$ & $\begin{array}{l}\text { Drafting/revision of the } \\
\text { manuscript for content, } \\
\text { including medical writing for } \\
\text { content, and analysis or } \\
\text { interpretation of data }\end{array}$ \\
\hline $\begin{array}{l}\text { Maria A. } \\
\text { Nagel, MD }\end{array}$ & $\begin{array}{l}\text { Department of Neurology, } \\
\text { University of Colorado, } \\
\text { Aurora, CO; Department of } \\
\text { Ophthalmology, University of } \\
\text { Colorado, Aurora, CO }\end{array}$ & $\begin{array}{l}\text { Drafting/revision of the } \\
\text { manuscript for content, } \\
\text { including medical writing for } \\
\text { content; study concept or } \\
\text { design; analysis or } \\
\text { interpretation of data; } \\
\text { additional contributions: } \\
\text { study supervision or } \\
\text { coordination; and obtaining } \\
\text { funding }\end{array}$ \\
\hline
\end{tabular}

\section{References}

1. Nagel MA, Traktinskiy I, Azarkh Y, et al. Varicella zoster virus vasculopathy: analysis of virus-infected arteries. Neurology. 2011;77(4):364-370.

2. Nagel MA, Bubak AN. Varicella zoster virus vasculopathy. J Infect Dis. 2018;218(S2): S107-S112.

3. Nagel MA, Traktinskiy I, Stenmark KR, Frid MG, Choe A, Gilden D. Varicella-zoster virus vasculopathy: immune characteristics of virus-infected arteries. Neurology. 2013; 80(1):62-68.

4. Jones D, Blackmon A, Neff CP, et al. Varicella-zoster virus downregulates programmed death ligand 1 and major histocompatibility complex class I in human brain vascular adventitial fibroblasts, perineurial cells, and lung fibroblasts. J Virol. 2016; 90(23):10527-10534.

5. Jones D, Neff CP, Palmer BE, Stenmark K, Nagel MA. Varicella zoster virus-infected cerebrovascular cells produce a proinflammatory environment. Neurol Neuroimmunol Neuroinflamm. 2017;4(5):e382.

6. Jana M, Palencia CA, Pahan K. Fibrillar amyloid-beta peptides activate microglia via TLR2: implications for Alzheimer's disease. J Immunol. 2008;181(10):7254-7262.

7. Bubak AN, Como CN, Coughlan CM, et al. Varicella-Zoster virus infection of primary human spinal astrocytes produces intracellular amylin, amyloid- $\beta$, and an amyloidogenic extracellular environment. J Infect Dis. 2020;221(7):1088-1097.

8. Bubak AN, Beseler C, Como CN, et al. Acute zoster plasma contains elevated amyloid, correlating with $A \beta 42$ and amylin levels, and is amyloidogenic. J Neurovirol. 2020;26(3):422-428.

9. Bubak AN, Beseler C, Como CN, et al. Amylin, A $\beta 42$, and amyloid in varicella Zoster virus vasculopathy cerebrospinal fluid and infected vascular cells. J Infect Dis. 2021; 223(7):1284-1294.

10. Mescher T, Boyer PJ, Bubak AN, Hassell JE Jr, Nagel MA. Detection of varicella zoster virus antigen and DNA in two cases of cerebral amyloid angiopathy. J Neurol Sci. $2021 ; 422: 117315$. 
11. Bubak AN, Como CN, Blackmon AM, et al. Varicella zoster virus induces nuclear translocation of the neurokinin-1 receptor, promoting lamellipodia formation and viral spread in spinal astrocytes. J Infect Dis. 2018;218(8):1324-1335.

12. Langmead B, Trapnell C, Pop M, Salzberg SL. Ultrafast and memory-efficient alignment of short DNA sequences to the human genome. Genome Biol. 2009;10(3):R25.

13. Trejo CL, Babić M, Imler E, et al. Extraction-free whole transcriptome gene expression analysis of FFPE sections and histology-directed subareas of tissue. PLoS One. 2019;14(2):e0212031.

14. Love MI, Huber W, Anders S. Moderated estimation of fold change and dispersion for RNA-Seq data with DESeq2. Genome Biol. 2014;15(12):550.

15. Tarazona $S$, Furió-Tarí $\mathrm{P}$, Turrà $\mathrm{D}$, et al. Data quality aware analysis of differential expression in RNA-seq with NOISeq R/Bioc package. Nucleic Acids Res. 2015;43(21): e140.

16. Federico A, Monti S. hyperR: an R package for geneset enrichment workflows. Bioinformatics. 2020;36(4):1307-1308.

17. Subramanian A, Tamayo P, Mootha VK, et al. Gene set enrichment analysis: a knowledge-based approach for interpreting genome-wide expression profiles. Proc Natl Acad Sci U S A. 2005;102(43):15545-15550.

18. Ouwendijk WJD, Dekker LJM, van den Ham HJ, et al. Analysis of virus and host proteomes during productive HSV-1 and VZV infection in human epithelial cells. Front Microbiol. 2020;11:1179.

19. R Core Team. R. A Language and Environment for Statistical Computing. R Foundation for Statistical Computing; 2020. www.R-project.org/.

20. Mahalingam R, Wellish M, Cohrs R, et al. Expression of protein encoded by varicellazoster virus open reading frame 63 in latently infected human ganglionic neurons. Proc Natl Acad Sci U S A. 1996;93(5):2122-2124.

21. Liberzon A, Subramanian A, Pinchback R, Thorvaldsdóttir H, Tamayo P, Mesirov JP. Molecular signatures database (MSiDB) 3.0. Bioinformatics. 2011;27(12):1739-1740.

22. Lee CW, Chuang LS, Kimura S, et al. RUNX3 functions as an oncogene in ovarian cancer. Gynecol Oncol. 2011;122(2):410-417.

23. Basagoudanavar SH, Thapa RJ, Nogusa S, Wang J, Beg AA, Balachandran S. Distinct roles for the NF- $\mathrm{kB}$ RelA subunit during antiviral innate immune responses. J Virol. 2011;85(6):2599-2610.

24. Kim Y, Nam YJ, Lee C. Analysis of the SREBF2 gene as a genetic risk factor for vascular dementia. Am J Med Genet B Neuropsychiatr Genet. 2005;139B(1):19-22.

25. Wei $\mathrm{K}, \mathrm{Che} \mathrm{N}$, Chen F. Myocardin-related transcription factor B is required for normal mouse vascular development and smooth muscle gene expression. Dev Dyn. 2007;236(2):416-425

26. Nagel MA, Choe A, Rempel A, Wyborny A, Stenmark K, Gilden D. Differential regulation of matrix metalloproteinases in varicella zoster virus-infected human brain vascular adventitial fibroblasts. J Neurol Sci. 2015;358(1-2):444-446.

27. Li M, Riddle SR, Frid MG, et al. Emergence of fibroblasts with a proinflammatory epigenetically altered phenotype in severe hypoxic pulmonary hypertension. J Immunol. 2011;187(5):2711-2722.

28. Eleftheriou D, Moraitis E, Hong Y, et al. Microparticle-mediated VZV propagation and endothelial activation: mechanism of VZV vasculopathy. Neurology. 2020;94(5): e474-e480.
29. Nagel MA, James SF, Traktinskiy I, et al. Inhibition of phosphorylated-STAT1 nuclear translocation and antiviral protein expression in human brain vascular adventitial fibroblasts infected with varicella-zoster virus. J Virol. 2014;88(19):11634-11637.

30. Bubak AN, Como CN, Blackmon AM, Jones D, Nagel MA. Varicella zoster virus differentially alters morphology and suppresses proinflammatory cytokines in primary human spinal cord and hippocampal astrocytes. J Neuroinflammation. 2018;15(1): 318.

31. Rannikmäe K, Kalaria RN, Greenberg SM, et al. APOE associations with severe CAAassociated vasculopathic changes: collaborative meta-analysis. J Neurol Neurosurg Psychiatry. 2014;85(3):300-305.

32. Wozniak MA, Shipley SJ, Dobson CB, et al. Does apolipoprotein E determine outcome of infection by varicella zoster virus and by Epstein Barr virus? Eur J Hum Genet. 2007;15(6):672-678.

33. Yankner BA, Lu T, Loerch P. The aging brain. Annu Rev Pathol. 2008;3:41-66.

34. Silverberg GD, Messier AA, Miller MC, et al. Amyloid efflux transporter expression at the blood-brain barrier declines in normal aging. J Neuropathol Exp Neurol. 2010; 69(10):1034-1043.

35. Guela $\mathrm{C}, \mathrm{Wu} \mathrm{CK}$, Saroff $\mathrm{D}$, et al. Aging renders the brain vulnerable to amyloid $\beta$-protein neurotoxicity. Nat Med. 1998;4(7):827-831.

36. Floden AM, Combs CK. Microglia demonstrate age-dependent interaction with amyloid- $\beta$ fibrils. J Alzheimers Dis. 2011;25(2):279-293.

37. Niie EG, Boelen E, Stassen FR, Steinbusch HW, Borchelt DR, Streit WJ. Ex vivo cultures of microglia from young and aged rodent brain reveal age-related changes in microglial function. Neurobiol Aging. 2012;33(1):195.e112.

38. Spittau B. Aging microglia-phenotypes, functions and implications for age-related neurodegenerative diseases. Front Aging Neurosci. 2017;9:194.

39. Tsai MC, Cheng WL, Sheu JJ, et al. Increased risk of dementia following herpes zoster ophthalmicus. PLoS One. 2017;12(11):e0188490.

40. Chen VC, Wu SI, Huang KY, et al. Herpes zoster and dementia: a nationwide population-based cohort study. J Clin Psychiatry. 2018;79(1):16m11312.

41. Lopatko Lindman K, Hemmingsson ES, Weidung B, et al. Herpesvirus infections, antiviral treatment, and the risk of dementia-a registry-based cohort study in Sweden. Alzheimers Dement (NY). 2021;7(1):e12119.

42. Ho JD, Lin HC, Kao LT. Increased risk of neovascular age-related macular degeneration in patients with herpes zoster ophthalmicus: a retrospective cohort study. Acta Ophthalmol. 2019;97(2):e321-e322.

43. Munoz-Quiles C, López-Lacort M, Ampudia-Blasco FJ, Diez-Domingo J. Risk and impact of herpes zoster on patients with diabetes: a population-based study, 20092014. Hum Vaccin Immunother. 2017;13(11):2606-2611.

44. Westermark P, Wilander E, Westermark GT, Johnson KH. Islet amyloid polypeptidelike immunoreactivity in the islet B cells of type 2 (non-insulin-dependent) diabetic and non-diabetic individuals. Diabetologia. 1987;30(11):887-892.

45. Narita R, Toshimori H, Nakazato M, et al. Islet amyloid polypeptide (IAPP) and pancreatic islet amyloid deposition in diabetic and non-diabetic patients. Diabetes Res Clin Pract. 1992;15(1):3-14.

46. Clark A, Chargé SB, Badman MK, de Koning EJ. Islet amyloid in type 2 (non-insulindependent) diabetes. APMIS. 1996;104(1):12-18. 


\section{Neurology ${ }^{\oplus}$ \\ Neuroimmunology \& Neuroinflammation}

Targeted RNA Sequencing of VZV-Infected Brain Vascular Adventitial Fibroblasts Indicates That Amyloid May Be Involved in VZV Vasculopathy

Andrew N. Bubak, Christina N. Como, James E. Hassell, Jr, et al.

Neurol Neuroimmunol Neuroinflamm 2022;9;

DOI 10.1212/NXI.0000000000001103

This information is current as of November 10, 2021

Neurol Neuroimmunol Neuroinflamm is an official journal of the American Academy of Neurology.

Published since April 2014, it is an open-access, online-only, continuous publication journal. Copyright

Copyright $\odot 2021$ The Author(s). Published by Wolters Kluwer Health, Inc. on behalf of the American

Academy of Neurology.. All rights reserved. Online ISSN: 2332-7812.

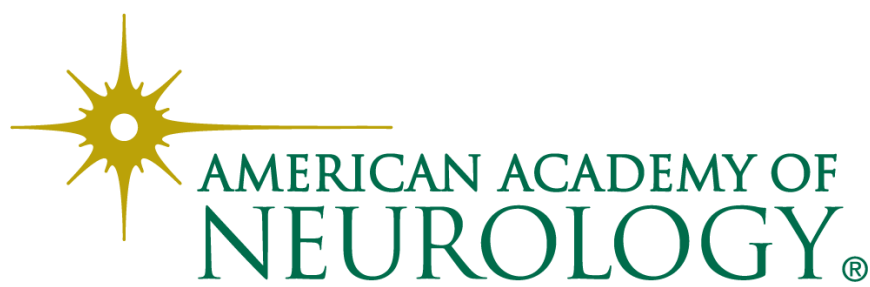




\section{Updated Information \& Services}

References

\section{Subspecialty Collections}

\section{Permissions \& Licensing}

\section{Reprints}

including high resolution figures, can be found at: http://nn.neurology.org/content/9/1/e1103.full.html

This article cites 45 articles, 9 of which you can access for free at: http://nn.neurology.org/content/9/1/e1103.full.html\#\#ref-list-1

This article, along with others on similar topics, appears in the following collection(s):

\section{All Cerebrovascular disease/Stroke}

http://nn.neurology.org//cgi/collection/all_cerebrovascular_disease_str oke

\section{All Cognitive Disorders/Dementia}

http://nn.neurology.org//cgi/collection/all_cognitive_disorders_dementi a

\section{Gene expression studies}

http://nn.neurology.org//cgi/collection/gene_expression_studies

\section{Vasculitis}

http://nn.neurology.org//cgi/collection/vasculitis

\section{Viral infections}

http://nn.neurology.org//cgi/collection/viral_infections

Information about reproducing this article in parts (figures,tables) or in its entirety can be found online at:

http://nn.neurology.org/misc/about.xhtml\#permissions

Information about ordering reprints can be found online: http://nn.neurology.org/misc/addir.xhtml\#reprintsus

Neurol Neuroimmunol Neuroinflamm is an official journal of the American Academy of Neurology.

Published since April 2014, it is an open-access, online-only, continuous publication journal. Copyright

Copyright $\odot 2021$ The Author(s). Published by Wolters Kluwer Health, Inc. on behalf of the American Academy of Neurology.. All rights reserved. Online ISSN: 2332-7812.

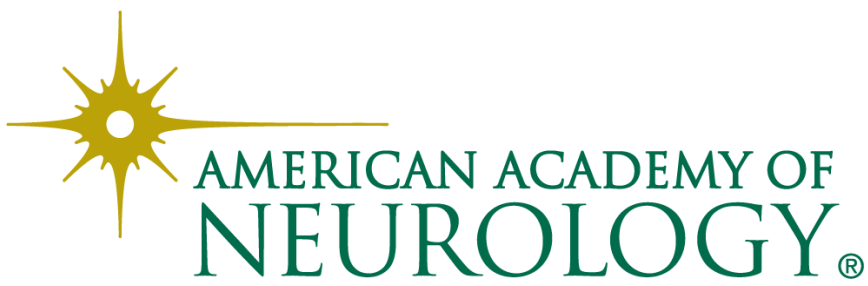

